\title{
Abaixo de zero: psicanálise, política e o "deficit de negatividade" em Axel Honneth
}

Vladimir Safatle

Professor do Departamento de Filosofia da USP 

Os últimos vinte anos do debate filosófico e social viram a hegemonia do conceito de reconhecimento como operador central para a compreensão da racionalidade das demandas políticas. Recuperado, pela primeira vez nos anos trinta, através das leituras hegelianas de Alexandre Kojève com seus desdobramentos, entre outros, na psicanálise de Jacques Lacan e nas filosofias de Jean Hyppolite, Georges Bataille, Maurice Merleau-Ponty e, um pouco mais distante, Jean-Paul Sartre ${ }^{1}$ o conceito só foi explorado sistematicamente em sua dimensão propriamente política a partir do início dos anos noventa, em especial pela Terceira geração da Escola de Frankfurt (Axel Honneth) e por filósofos que sofreram influência de Hegel, como Charles Taylor. Teóricos políticos que seguiram os cursos de Kojève, como Raymond Aron e Eric Weil, não se notabilizaram pela exploração sistemática das potencialidades de uma teoria do reconhecimento. Até os anos noventa, o conceito se demonstrara profícuo principalmente em seus usos clínicos (o problema do reconhecimento do desejo na clínica psicanalítica de Jacques Lacan²) e ético (através dos debates sobre a ética da alteridade, especialmente em Emmanuel Lévinas e Martin Buber). As potencialidades de seu uso político serão impulsionadas, na verdade, pelo aparecimento de dois textos em 1992: Luta por reconhecimento, de Axel Honneth e Multiculturalismo e as "politicas do reconhecimento", de Charles Taylor. A partir deles, o conceito hegeliano de Anerkennung parecia enfim fornecer uma orientação normativa para o desenvolvimento progressivo das lutas sociais.

Esta segunda recuperação constituiu-se, no entanto, através de uma peculiar operação de reinstauração. Tudo se passou como

1 Ver ARANTES 1991; DESCOMBES 1979, BUTLER e ROTH 1988.

2 A este respeito, tomo a liberdade de remeter a Safatle 2006. 
se a vertente propriamente francesa do debate, presente desde os anos trinta, devesse ser, em larga medida, ignorada para que o conceito pudesse, enfim, encontrar a força política que lhe era de direito. Isto pode nos explicar por que as referências de Honneth e Taylor a, por exemplo, Kojève ou a Lacan são, na maioria dos casos, marcadas pela concisão e pelo desinteresse soberano, mesmo que o psicanalista francês seja alguém que, como Honneth, procurou pensar o problema do reconhecimento articulando hegelianismo e psicanálise. Assim, vários pesquisadores contemporâneos aceitaram a versão de que as primeiras leituras sobre o reconhecimento não passavam de uma sucessão de erros de avaliação e equívocos que melhor seria ignorar.

Há de se perguntar, no entanto, se tal recusa não teria consequências políticas importantes, se este silêncio não estaria, na verdade, a expressar a consciência muda de dois desdobramentos possíveis de um mesmo conceito de matriz hegeliana. Se este for o caso, não será a primeira vez que os mesmos conceitos hegelianos acabarão por organizar polos políticos opostos.

Mas para analisar tal hipótese, devemos expor as possibilidades políticas inexploradas da recuperação francesa do conceito de reconhecimento. Neste caso, gostaria de me concentrar em sua matriz lacaniana por entender que ela é particularmente frutífera para tal discussão33. Por outro lado, uma operação desta natureza, para não se reduzir a um exercício de correção de historiografia conceitual, deveria levar em conta os limites da real força política de transformação social presente na recuperação frankfurtiana do reconhecimento. Estes serão, pois, os dois objetivos principais deste texto.

\footnotetext{
3 Os usos políticos do pensamento lacaniano foram desenvolvidos principalmente por: Alain Badiou, Slavoj Zizek e Ernesto Laclau. No entanto, nenhum dos três autores parte das discussões lacanianas sobre o problema do reconhecimento, talvez por admitirem que tais discussões estariam muito ligadas a um período do pensamento lacaniano que teria sido relativizado pelo próprio Lacan a partir dos anos sessenta. De fato, esta não é a única leitura possível, o que nos leva a explorar o problema apresentado por este texto.
} 
A sugestão de pensar conjuntamente Honneth e Lacan a respeito do problema do reconhecimento tem uma razão de base. Pois teorias do reconhecimento são normalmente fundadas em teorias da socialização e da individuação. Elas pedem uma certa antropologia no mais das vezes marcada pela reflexão sobre processos de maturação em direção à pessoa individualizada, de ontogênese das capacidades prático-cognitivas e de constituição do Eu autônomo. Como se processos de reconhecimento devessem necessariamente ser lidos como movimentos em direção à afirmação de uma autonomia e individualidade conquistadas. Neste sentido, a teoria do reconhecimento de Axel Honneth, com seus empréstimos massivos à antropologia psicanalítica de Donald Winnicott, de Hans Loewald e de outros teóricos da teoria das relações de objeto, é um exemplo ilustrativo e, certamente, um dos casos mais bens construídos neste sentido.

No entanto, a psicanálise pode nos fornecer uma compreensão radicalmente distinta de tais processos de socialização e individuação tais como apresentados por Honneth, isto se levarmos em conta Jacques Lacan. Gostaria de mostrar como, ao mudar tal base psicanalítica, temos uma visão distinta não apenas da dinâmica de socialização dos desejos e pulsões, mas das consequências políticas do conceito de reconhecimento. Pois tal reflexão pode fornecer uma base empírica e material para a ideia de que sujeitos procuram ser reconhecidos em um campo político fora dos processos culturais de produção de identidades. Mesmo que tais formulações não sejam encontradas de maneira literal em Lacan, gostaria de abrir caminho para mostrar que esta é uma consequência possível de suas posições. Devido a questões de tamanho, este artigo se contentará em explorar os problemas do recurso honnethiano à psicanálise, oferecendo certas alternativas que levem em conta a psicanálise lacaniana. Em uma segunda ocasião, será possível explorar de maneira sistemática os desdobramentos políticos de tal procedimento crítico. Desta forma, espera-se mostrar a urgência de recuperar, de maneira mais generosa, as 
potencialidades internas a certas correntes da primeira reatualização do conceito de reconhecimento operada a partir dos anos trinta na França.

\section{Estar doente}

Este embate em torno da matriz psicanalítica da reflexão sobre o reconhecimento deve ser visto como uma questão central. Lembremos, a este respeito, como Honneth insiste que a psicanálise forneceria, em seu nível normativo, um conceito antropológico de ser humano que, por dar lugar apropriado aos vínculos inconscientes e libidinais do indivíduo, não corre o risco de sucumbir a um moralismo idealizado. Daí uma afirmação como: "para se defender contra as ilusões de uma moralidade da razão, a Teoria Crítica deve ser suplementada por uma espécie de psicologia moral guiada por intuições psicanalíticas" (Honneth 2010, p. 253). Tais ilusões morais estariam presentes em visões do comportamento humano incapazes de levar em conta as dimensões inconscientes e profundamente conflitivas das motivações que impulsionam sujeitos a agir e escolher, visões que preferem referendar normatividades antropológicas fundadas em uma noção de autonomia construída através, por exemplo, de clivagens estritas entre vontade livre e desejo patológicos, entre razão, afeto e sensibilidade.

No entanto, há de se perguntar se, de fato, Honneth escapa de tal peso de pressupostos morais não tematizados quando recorre à psicanálise. Sua maneira de compreender a autonomia produzida ao final de um processo bem sucedido de maturação psíquica em chave não muito distante da moralidade pós-convencional de moldes kantianos, suas razões para recusar a teoria freudiana das pulsões e a natureza traumática da sexualidade, assim como sua maneira de sustentar que o caráter necessariamente inter-relacional da constituição do Eu seria prova maior da natureza 
intrinsecamente sociável e cooperativa dos sujeitos 4 talvez evidenciem uma moralidade idealizada, ligada à perpetuação de uma visão profundamente normativa presente na elevação da racionalidade comunicacional a horizonte regulador privilegiado para a construção de uma vida racional e dos processos de emancipação. Moralidade que acaba por perder o que a experiência clínica psicanalítica tem de mais transformador. Pois é possível que a verdadeira contribuição da psicanálise não esteja ligada à descoberta do inconsciente ou da sexualidade infantil, com uma consequente visão mais complexa da motivação do comportamento. Ou seja, sua principal contribuição não está no desenvolvimento de uma antropologia mais elaborada, mas em uma nova abordagem clínica. Insistir no caráter inovador da abordagem clínica psicanalítica é maneira de se perguntar se não deveríamos levar tal dimensão em conta na organização das reflexões sobre o político.

Por exemplo, uma das contribuições clínicas mais inovadoras da psicanálise consiste em defender que a experiência do patológico é instauradora da condição humana e a via privilegiada para conhecermos nossos processos de formação, assim como os traços de nossas estruturas de comportamento5. Honneth parece levar em conta algo desta via quando lembra da importância de um certo "ir e vir entre diagnóstico de patologias e análise da norma-

4 Sobre este último ponto, vale para Honneth a crítica de Joel Whitebook a respeito dos relacionistas e intersubjetivistas: "Eles acreditam que, mostrando o eu como produto de interação, eles mostrarão também que o eu é intrinsecamente sociável. O pressuposto não assumido é que interação equivale à mutualidade, ou seja, que, se o eu é um produto de interação, então ele é intrinsecamente mutualístico" (Whitebook 2008, p. 382 ).

5 O que não poderia ser diferente para alguém que acreditava que a conduta patológica expõe, de maneira ampliada, o que está realmente em jogo no processo de formação das condutas sociais gerais. É desta forma que devemos interpretar uma metáfora maior de Freud : "Se atiramos ao chão um cristal, ele se parte, mas não arbitrariamente. Ele se parte, segundo suas linhas de clivagem, em pedaços cujos limites, embora fossem invisíveis, estavam determinados pela estrutura do cristal" (FREUD, Sigmund; Gesammelte Werke (GW) vol. XV, Frankfurt: Fischer, 1999, p. 64) O patológico é este cristal partido que, graças à sua quebra, fornece a inteligibilidade do comportamento definido como normal. Para um bom comentário deste problema em Freud, ver: Van Haute e De Vçeminck 2013. 
lidade, entre etiologia e teoria da personalidade" (Honneth 2008, p. 160) próprio ao pensamento freudiano. Ele cita, como exemplos, a proximidade entre luto e melancolia ou, principalmente, a generalização dos mecanismos de recalque para todo e qualquer sujeito. Generalização que Honneth chama de "antropologização do conflito potencial do desejo recalcado" (Honneth 2008, p. 161). No entanto, este ir e vir entre normal e patológico é compreendido por Honneth como expressão da necessidade da personalidade normal ser capaz de, esporadicamente, reativar mecanismos psíquicos próprios da primeira infância. Um pouco como se o patológico fosse ainda pensado, em chave desenvolvimentista, como figura da regressão a estados arcaicos do comportamento infantil.

Haveria outra maneira, no entanto, de pensar a reformulação freudiana das relações entre normal e patológico. Pois admitir que a experiência do patológico e instauradora da condição humana implica, entre outras coisas, assumir o caráter irredutível do que chamamos de "sintoma". Wilheim Reich, por exemplo, lembrará que os mecanismos de defesa do Eu, assim como seus traços de caráter que compõem o cerne da personalidade psicológica, são constituídos das mesma forma que os sintomas ${ }^{6}$. Tais colocações abrem as portas para transformar a experiência do patológico, assim como do ato de produzir sintomas, em expressões fundamentais da condição humana por serem produções de respostas singulares, de construções insubstituíveis, de modos de desejar e de agir. Isto poderia nos levar a afirmar, tal como sugere Lacan, que “(...) o eu está estruturado exatamente como um sintoma. No interior do sujeito, não é senão um sintoma privilegiado. É o sintoma humano por excelência, é a doença mental do homem" (Lacan 1986, p. 25). Neste caso em que o próprio Eu aparece com

6 Daí por que: “A forma das reações do ego, que difere de um caráter para outro mesmo quando os conteúdos das experiências são semelhantes, pode ser remontada às experiências infantis, da mesma maneira que o conteúdo dos sintomas e das fantasias"( Reich 2001, p. 53). 
sua organização psíquica como um sintoma privilegiado, não é sequer possível falar em distinções entre personalidade e patologia. No limite, a psicanálise acaba por deixar de ser vista como mais uma psicoterapia focada na dissolução de sintomas, pois isto a levaria a anular uma dimensão fundamental da produtividade da experiência humana (Lacan 2010).

Duas consequências principais derivam-se daqui. Primeiro, a ideia de irredutibilidade do sintoma e do patológico implica o reconhecimento da irredutibilidade de experiências de heteronomia, de fragmentação e de estranhamento. Isto pode levar nossos ideais atuais de normalidade social, ideais esses normalmente assentados na crença na força emancipadora dos conceitos de autonomia, unidade e autenticidade, a serem vistos, em larga medida, como matrizes de produção de sofrimento. Por não estar disposto a trilhar tal caminho, Honneth tende, entre outras coisas, a compreender o "negativismo" freudiano e sua tematização da relação dramática entre indivíduo e sociedade como mera expressão distorcida de uma visão proto-hobbesiana da fragilidade dos vínculos sociais diante da irracionalidade do comportamento humano. Irracionalidade que poderia ser, ao final de um processo bem sucedido de maturação, submetida às exigências normativas da razão.

A segunda consequência diz respeito a reconfiguração do processo clínico de cura. Aceita esta perspectiva lacaniana, talvez possamos nos aproximar de certas correntes epistemológicas que defendem um "nominalismo dinâmico"7 na compreensão de categorias clínicas ligadas ao psiquismo. Feito tal aproximação, diremos que sujeitos não sofrem exatamente por terem sintomas. Eles sofrem por compreenderem tais sintomas como mera

7 Como podemos encontrar em Hacking, Ian; Historical ontology, Harvard University Press, 2004, p. 106. Ainda a este respeito, ver Davidson, Arnold; The emergence of sexuality: historical epistemology and the formation of concepts, Harvard University Press, 2004. 
expressão de uma forma de estar doente. Pois estar doente é, a princípio, assumir uma identidade com forte força performativa. Ao compreender-se como "neurótico", "depressivo" ou portador de "transtorno de personalidade borderline", o sujeito nomeia a si através de um ato de fala capaz de produzir performativamente efeitos novos, de ampliar impossibilidades e restrições. Uma patologia mental não descreve uma espécie natural (natural kind) como talvez seja o caso de uma doença orgânica como câncer ou mal de Parkinson. Como nos lembram Ian Hacking, ela cria performativamente uma nova situação na qual sujeitos se veem inseridos ${ }^{8}$.

Se este for de fato o caso, então poderemos dizer que uma dimensão fundamental do trabalho analítico consiste não em dissolver os sintomas, mas em dissolver o vínculo do sujeito à identidade produzida pela doença, o que permite aos sintomas perderem certos efeitos, diminuírem certas intensidades e se abrirem à possibilidade de produção de novos arranjos. Mas falamos ainda de sintomas, e não de normatividades partilhadas intersubjetivamente, porque a singularidade deste processo não nos leva à garantia de aprofundamento de relações cooperativas ou de consolidação de compreensão afetiva. Ela nos leva, ao contrário, à compreensão da fragilidade das interações, sobretudo quando pautadas pela enunciação de demandas individuais. Do ponto de vista social, a compreensão de que patologias mentais não são apenas desvios em relação a um padrão, seja através da falta, seja através do excesso, mas são processos instauradores de individualidades, nos leva a questionar a crença de que seres humanos seriam intrinsecamente sociáveis e cooperativos. Seres humanos são seres que precisam da experiência do patológico, ou seja, seres que precisam colocar-se fora da normalidade que define um campo distendido de coo-

8 Este é um importante ponto defendido por Ian Hacking, para quem, no que se refere a classificações de doenças mentais: "um tipo (kind) de pessoa vem à existência ao mesmo tempo que a própria categoria clínica (kind) foi inventada. Em alguns casos, nossas classes e classificações conspiram para aparecer uma suportada pela outra" (Hacking 2004, p. 106). 
peração para produzirem algo de fundamental em relação às suas experiências do desejo, da ação e do uso da linguagem. Talvez isto explique um pouco por que Lacan se recusa de maneira tão taxativa em ver a psicanálise como uma "terapia”.

De fato, isto traz, entre outras coisas, consequências políticas fundamentais por exigir uma profunda recompreensão do que podemos entender por reconhecimento social e seus limites. Pois, se devemos admitir a fragilidade das interações quando pautadas pela enunciação de demandas individuais, assim como devemos aceitar a ideia de que individualidades seriam organizadas a partir de sintomas que se confundem com a estrutura mesma da personalidade, então duas saídas se colocam: aceitar que a experiência do reconhecimento estaria estruturalmente comprometida ou pensar que ela exige a superação de uma certa dimensão antropológica que fundamenta a institucionalização do conceito de pessoa. Tal segunda alternativa poderia nos levar, entre outras coisas, a procurar fundar a experiência do político para além da afirmação e do reconhecimento da individualidade organizada como personalidade. Gostaria de iniciar tal discussão mostrando quais os arranjos conceituais necessários para fundamentar psicanaliticamente tal perspectiva.

\section{A mãe de Honneth e a política de Winnicott}

Tendo esta perspectiva em vista, haverá duas tarefas privilegiadas se quisermos pensar o impacto das reflexões psicanalistas

9 Notemos como o frankfurtiano que mais se aproxima, por outras razões, desta forma de pensar o problema é Adorno. Pois é dele a afirmação de que: "as neuroses deveriam, de fato, segundo sua forma, ser deduzidas da estrutura de uma sociedade em que elas não podem ser eliminadas. Mesmo a cura bem-sucedida carrega o estigma do danificado, da vã adaptação pateticamente exagerada. O triunfo do eu é o da ofuscação pelo particular. Este é o fundamento da inverdade objetiva de toda psicoterapia, que incita os terapeutas à fraude. Na medida em que o curado se assemelha à totalidade insana, torna-se ele mesmo doente, mas sem que aquele para quem a cura fracassa seja por isso mais saudável" (ADORNO, Theodor; "Sobre a relação entre psicologia e sociologia” In: Escritos de psicologia e psicanálise, São Paulo: Unesp (no prelo). 
na configuração das potencialidades políticas do conceito de reconhecimento. A primeira consiste em defender a tese de que a personalidade psicológica e os atributos da pessoa individualizada são estruturados como sintomas defensivos, explorando as consequências de tal posição para uma teoria do reconhecimento. Pois isto implica aceitar que o problema do reconhecimento não deveria estar centrado no reconhecimento dos atributos individualizados da pessoa.

A segunda tarefa passa pela defesa da existência de um elemento irredutivelmente pré-pessoal na estrutura humana, chamado por Lacan de "pulsão". Elemento que, devido à sua característica avessa à personalização, não se organiza sob a forma de sintomas. Na verdade, Lacan falará que a existência da pulsão exige a constituição de uma "subjetivação acéfala, uma subjetivação sem sujeito” (Lacan 1973, p. 169). Tal peculiar subjetivação sem sujeito (no sentido de uma subjetivação que não deve ser compreendida como expressão de um sujeito substancial previamente definido) nos permitiria justificar a necessidade de pensarmos modalidades de reconhecimento para além da forma institucionalizada da pessoa.

Uma maneira privilegiada de abordar a primeira tarefa passa pela crítica à tese da existência de uma intersubjetividade primária a guiar as relações de amor entre mãe e bebê; intersubjetividade capaz de fundamentar a construção segura da individualidade a ser reconhecida em esferas sociais para além do núcleo familiar. Se não houver tal intersubjetividade como fundamento para a construção da individualidade, fica aberto o espaço para defendermos a existência de uma natureza irredutivelmente conflitual das relações intersubjetivas. Natureza conflitual que seria expressa pela necessidade da pessoa psicológica estruturar-se como um organização defensiva de sintomas.

Já a segunda tarefa passa pela avaliação das críticas de Honneth à ideia freudiana de que a natureza humana pode ser compreendida a partir de uma teoria das pulsões. Na verdade, o problema 
central gira aqui em torno da existência de algo como uma "pulsão de morte". Por sua vez, a critica à pulsão de morte é articulada, entre outras coisas, a uma recusa em definir a "negatividade" como base compreensiva da estrutura do desejo humano. Esta crítica à negatividade traz consequências maiores na leitura proposta por Honneth a respeito do problema do reconhecimento em Hegel, em especial na Fenomenologia do Espírito. Desta forma, temos uma hipótese sobre os modelos gerais de relações intersubjetivas e outra sobre o sistema subjetivo de motivações para a ação $0^{10}$. Vejamos melhor cada um dos casos.

A tese da intersubjetividade primária serve para Honneth defender a existência de uma tendência fortemente cooperativa e comunicacional no interior das primeiras experiências de interação social. Por esta razão, ela é fundamental para o projeto de Honneth, assim como para sua crítica de modelos, a seu ver, insuficientes. O filósofo alemão deriva a tese da intersubjetividade primária da teoria das relações de objeto de Donald Winnicott e sua forma de compreender as relações de amor e de dependência mútua entre mãe e bebê. Tais relações de amor constituiriam uma base sólida para o desenvolvimento da capacidade de ser si mesmo em um outro. Desta forma:

a experiência intersubjetiva do amor abre o indivíduo a este estrato fundamental de segurança emocional (emotionalen Sichereit) que lhe permite não apenas experimentar, mas também exteriorizar (Äusserung)

10 Na verdade, encontramos tanto a hipótese de uma intersubjetividade primária quanto a crítica à negatividade estrutural da pulsão de morte já nos trabalhos de outro frankfurtiano, a saber, Herbert Marcuse. Por exemplo, para Marcuse, se o princípio de realidade fundado na repressão pulsional está vinculado inicialmente à internalização da Lei paternal e seus princípios simbólicos de organização, então no interior do fluxo libidinal simbiótico entre bebê e mãe poderíamos encontrar os vestígios de um outro modo de acesso à realidade. Marcuse fala de uma "atitude não de defesa e de submissão [pois estaríamos em uma relação de interdependência intersubjetiva entre mãe e bebê], mas de integral identificação com o meio" (Marcuse 1999, p. 199). Há uma certa continuidade de suas perspectivas com as teses defendidas por Honneth. 
suas próprias necessidades e sentimentos, assegurando assim a condição psíquica do desenvolvimento de todas as outras atitudes de respeito de si (Honneth 1992, p. 171).

Ou seja, segundo tal perspectiva, levamos para esferas mais amplas da vida social a crença na exteriorização tranquila de necessidades e sentimentos, uma crença que seria resultado da experiência intersubjetiva de amor e de afirmação de si presente inicialmente na relação entre mãe e bebê ${ }^{11}$. Tal relação poderia ser chamada de "intersubjetiva" por ela ser, ao menos segundo Honneth, simétrica. Isto significa que o bebê dependeria da mãe da mesma forma que a mãe dependeria do bebê, isto no interior de uma relação de "identificação emocional" onde a criança aprende a adotar a perspectiva de uma segunda pessoa. Tal mútua dependência poderia resolver-se através da consolidação de uma posição de cooperação e de segurança emocional que permitiria, à criança, desenvolver sua "consciência individual de si".

Neste sentido, um tema importante consiste em avaliar em até que ponto tal visão da relação entre mãe e bebê é uma construção idílica montada para legitimar a hipótese filosófica de uma intersubjetividade fundadora da condição humana. Pois, por exemplo, seguindo uma perspectiva que toma Lacan como ponto de partida, podemos defender que as primeiras relações intersubjetivas dificilmente podem ser descritas como relações simétricas. $\mathrm{Na}$ verdade, elas seriam assimétricas, já que a primeira posição subjetiva da criança é ser objeto das fantasias da mãe ${ }^{12}$, com toda sua carga de expectativas e frustrações violentas. Neste ponto, La-

11 Para funcionar, tal estratégia deve recusar as críticas que vêm, na família, principalmente um aparato disciplinar (Foucault 2010) e repressivo (Deleuze e Guattari 2014) cujas relações não serviriam de fundamento para pensarmos situações de emancipação social. Isto exigiria uma reatualização da crítica ao "familiarismo" tal como ela apareceu na filosofia francesa contemporânea.

12 Lacan desenvolveu de maneira extensiva este ponto, assim como as consequências do supereu materno (Lacan 1994). 
can aparece como uma espécie de continuador das considerações de Melanie Klein a respeito da estrutura fantasmática da relação entre mãe e bebê.

Notemos como a sobrevivência física do bebê depende do bem querer e do cuidado materno, o que significa que seu desamparo só pode ser controlado à condição de encontrar um lugar no interior das fantasias maternas, enquanto o mesmo não pode ser dito da mãe, a menos não sob o mesmo grau de intensidade. Esta situação faria com que as primeiras relações intersubjetivas fossem, na verdade, relações de dominação e servidão com as quais a criança deverá saber lidar, o que explica por que Lacan utiliza a estrutura da dialética hegeliana do Senhor e do Escravo para dar conta de tais relações responsáveis pela formação do Eu. Pois a criança deveria, em larga medida, adaptar-se à normatividade encarnada pelas exigências disciplinares maternas para sobreviver psíquica e fisicamente. Tal exigência disciplinar de adaptação explicaria, por sua vez, por que a criança precisa mobilizar, em mais de uma ocasião, a experiência da doença e a produção de sintomas para poder construir sua singularidade.

Uma estratégia possível para encaminhar tal querela passa pela reflexão sobre estudos recentes a respeito da natureza das primeiras relações de interação e suas consequências posteriores, o que gostaria de fazer de maneira mais sistemática em outra oportunidade $^{13}$. Mas notemos dois pontos. Primeiro, boa parte destes estudos expõem a existência de uma "proximidade afetiva" primária entre o bebê e aqueles responsáveis por seu cuidado. Bebês sabem que são objetos de atenção, eles se identificam mais facilmente e fortemente com o responsável por cuidados do que outros primatas. No entanto, tal proximidade afetiva não implica, necessariamente, relação de segurança no que diz respeito ao

13 Ver, por exemplo, Bebee e Lachmann 2002; Fonagy e Target 2007, p. 917-937, Tomasello 2003 e Braten 2007. 
sentido do desejo do outro e suas intermitências. Posso saber ser objeto de atenção, mas não se segue daí a segurança de que sempre serei tal objeto, de que não haverá outro sujeito a me desalojar da minha posição, de que sei o que devo fazer para conservar tal atenção e que, principalmente, sei o que tal atenção significa ${ }^{14}$. Por isto, a experiência de ser objeto do desejo do outro, em especial objeto de desejo materno, é desde o início fonte de angústia, não simplesmente fonte de segurança existencial. Daí por que Lacan afirmará existir "atrás do supereu paterno, um supereu materno ainda mais exigente, ainda mais opressivo, mais destruidor, mais insistente" (Lacan 1998, p. 165).

Por outro lado, vale a pena lembrar que mesmo a leitura honnethiana de Winnicott pode ser relativizada no que diz respeito à natureza cooperativa das relações primárias. Lembremos, por exemplo, como o psicanalista inglês afirmará:

No desenvolvimento corporal, o fator de crescimento é mais claro; no desenvolvimento da psique, por contraste, há a possibilidade do fracasso a cada momento, e na verdade é impossível que exista um crescimento sem distorções devidas a algum grau de fracasso na adaptação ambiental (Winnicott 1990, p. 47).

Se é impossível haver desenvolvimento sem algum grau de fracasso na adaptação ambiental, há de se perguntar se devemos realmente falar em uma exteriorização tranquila de necessidades e sentimentos, como quer Honneth. Fracassos implicam distorções e frustrações diante de demandas de adaptação. Isto pode significar a necessidade de saber lidar com limites nas expectativas de cooperação com o outro, ou seja, significa saber lidar com a in-

14 Daí por que: "Tal proximidade afetiva não pode ser caracterizada em termos de valências positivas ou negativas; ela não envolve um julgamento cognitivo ou um conjunto de inferências referentes ao valor que outros possam possuir: ao contrário, atitudes positivas, negativas ou mesmo indiferentes a respeito do outro dependem desta afetividade "não epistêmica" em relação ao outro" (Gallagher e Varga 2012, p. 255). 
segurança existencial vinda da compreensão de que a mãe não saberá responder a dimensões fundamentais do desejo do sujeito ${ }^{15}$.

É fato que Winnicott acredita, em vários momentos, que "uma adaptação extrema às necessidades do bebê pode ser feita pela mãe real sem ressentimento" (Winnicott 1990, p. 132). Tal adaptação bem sucedida permitiria que a criança não sucumbisse a uma desilusão profunda relativa às suas expectativas de reconhecimento gerando, com isto, uma situação patológica de insegurança existencial. Há de se perguntar, no entanto, se tal insistência winnicottiana na capacidade materna em propiciar uma peculiar "adaptação perfeita" não seria fonte suplementar de sofrimento e desajuste para a mãe, principalmente em uma época cada vez mais marcada pela recusa das gerações atuais em partilhar modelos tradicionais de maternidade, com a consequente insegurança em seu desempenho e a vulnerabilidade estrutural a depressões pós-parto ${ }^{16}$.

Mas mesmo que a posição de Winnicott não seja exatamente a que advogo aqui, ela está igualmente distante daquela na qual Honneth gostaria de colocá-la. Vale a pena lembrar, por exemplo, quais as consequências do fato da manifestação privilegiada do caráter bem sucedido da relação intersubjetiva entre mãe e bebê ser a constituição de estados transicionais nos quais a criança pode sustentar, diante do outro, a ilusão de ter criado os objetos do mundo externo. Winnicott vê em tais estados a fonte dos fenômenos religiosos e artísticos. No entanto, arte e religião não são exatamente fenômenos intersubjetivos, mas fenômenos que se

15 Assim: "quando existe uma dificuldade, a mãe e o bebê podem levar muito tempo até conseguir se entender um com o outro, e frequentemente acontece que a mãe e o bebê falhem desde o princípio, e assim sofram (ambos) as consequências dessa falha por muitos anos, e às vezes para sempre" (Winnicott 1990, p. 123).

16 "As análises mais adequadas da maioria dos estudos concluem que algo como 7,1\% das mulheres deve experimentar um episódio depressivo maior nos primeiros três meses pós-parto. Se incluirmos depressões menores, a taxa própria ao período de três meses sobe para 19,2\%" (O’Hara 2009, p. 1265). Ou seja, uma em cada cinco mães passarão por uma experiência depressiva no cuidado de seu filho. 
inscrevem no limite da estrutura comunicacional da linguagem. O que Winnicott alude ao afirmar, em sua linguagem bastante concreta:

Alguém que exija tamanha tolerância numa idade posterior é chamado de louco. Na religião e nas artes, vemos esta reivindicação socializada, de modo que o indivíduo não é chamado de louco e pode usufruir, no exercício da religião ou na prática e apreciação das artes, do descanso necessário aos seres humanos em sua eterna tarefa de discriminar entre os fatos e a fantasia (Winnicott 1990, p. 127).

Podemos interpretar tal colocação afirmando que o tipo de vinculo social criado a partir dos desdobramentos da relação de amor entre mãe e bebê é de uma ordem muito específica, que talvez não sirva como base para a fundamentação dos vínculos sociais em geral, o que Honneth não parece aceitar ${ }^{17}$. Pois, para encontrar aqui os fundamentos de uma política, devemos esquecer que a relação de circulação de fantasias no espaço transicional sustentado por uma "mãe suficientemente boa" é, entre outras coisas, exclusivista, como são exclusivistas as relações próprias às comunidades religiosas e às experiências artísticas. Se quisermos seguir a perspectiva de Winnicott, devemos dizer que só poderão sustentar este vínculo aqueles que portarem os traços, bastante específicos, de comportamento e caráter relativos à mãe suficientemente boa que tivemos e que nos permitiu "ter a ilusão de encontrar na realidade aquilo que criamos (alucinamos)" (Id., Ibid. 1990, p. 135). Como nem todos podem entrar neste molde (por terem, na melhor das hipóteses, experiências concretas distintas do que foi uma mãe suficientemente boa) e assegurar tal ilusão,

17 Ao contrário, ele quer afirmar que: "A fascinante observação de Winnicott pode ser expandida a fim de incluir, além da arte e da religião, a intersubjetividade grupal como um espaço de experiência que dissolve os limites entre realidade externa e interna" (Honneth 2010, p. 274). 
segue-se o exclusivismo da relação, assim como o interesse político limitado que tal reflexão pode ter.

Por outro lado, há de se lembrar aqui que não se passa impunemente das artes e religião (manifestações relativas ao campo da cultura) às relações intersubjetivas propriamente políticas. Não é por outra razão que Winnicott deve salientar que, do ponto de vista da relações intersubjetivas da vida ordinária, as demandas presentes na arte e na religião são insanas. Elas são permitidas apenas como experiências compensatórias e não como experiências que poderiam induzir transformações globais no campo partilhado do político. Tais transformações exigiriam uma visão na qual vínculos comunitários religiosos poderiam fundamentar ordens sociais, ou na qual experiências estéticas poderiam, por sua vez, reconstruir a natureza de nossas expectativas comunitárias. Não parece que Honneth queira seguir alguma destas duas vias.

\section{Lutas sem risco}

Mesmo assim, Honneth precisa criar a imagem de um processo de reconhecimento que se realiza na confirmação de si pelo outro para fundamentar sua filosofia política. Pois a segurança emocional gerada pelo caráter bem sucedido das demandas de amor no interior do núcleo familiar estaria na base das demandas sociais de reconhecimento da autonomia individual e da afirmação de seus sistemas particulares de interesse. Elas estariam também na base da profunda sensibilidade dos sujeitos para experiências de desprezo e de injustiça. Desta forma, Honneth constrói uma antropologia psicanalítica para orientar processos de interação social onde não há lugar para antagonismos insuperáveis. Antropologia profundamente familiarista capaz de fornecer os fundamentais morais dos conflitos sociais. Mas neste caso, um familiarismo focado, em larga medida, em apenas um dos polos da matriz de socialização da família burguesa, a saber, a mãe, deixando de fora a natureza conflitual da relação pai-mãe e suas consequências para a formação dos filhos. 
Honneth espera que tal antropologia psicanalítica seja compatível com aspectos da reflexão sobre conflitos sociais no interior da tradição dialética de Hegel e Marx. Para ele, a ideia fundamental de Hegel seria: "a luta pelo reconhecimento constitui a força moral que impulsiona a realidade vital social humana em direção ao desenvolvimento e ao progresso" (Honneth 1992, p. 227). Pois a experiência moral de desprezo de minha dignidade de sujeito agente e desejante estaria na origem dos movimentos de resistência social e de sublevação coletiva. Sendo assim, o progresso histórico em direção à liberdade seria a história da realização, cada vez mais universal, de uma antropologia psicanaliticamente orientada. Mas para Hegel entrar neste horizonte serão necessários alguns ajustes dificilmente sustentáveis sem perdas importantes em sua teoria.

A principal delas está na maneira, no mínimo peculiar, com a qual Honneth lê a dialética hegeliana do senhor e do escravo. Honneth reconhece na referida dialética um "fato transcendental" que aparece como pré-requisito para toda a sociabilidade humana. Mas, em suas mãos, tal dialética será o movimento de conquista paulatina de uma capacidade de "auto-restrição" através da qual aprendo a limitar as ilusões de onipotência de meu desejo ao entrar em contato com a irredutibilidade do desejo do outro. Desta forma: "ego e alter ego reagem um ao outro restringindo ou negando seus respectivos desejos egoístas" (Id., 2010, p. 30).

Há de se admirar esta transformação do desdobramento da dialética do senhor e do escravo na afirmação de uma verdadeira moralidade de escoteiro. Mas, para que tal interpretação seja possível, Honneth precisa, entre tantas outras coisas, distorcer o que Hegel entende por "negatividade em si" (Negativität an ihm), lendo-a como uma espécie de autonegação através da qual sujeitos aprendem a restringir seus próprios desejos. No entanto, tal conceito indica a existência, para Hegel, de uma realidade ontológica da negação fundamental para compreendermos a natureza profundamente indeterminada do desejo. Todas as vezes que Hegel 
fala de uma: "negação em si que só tem um ser enquanto negação reportando-se a si” (Hegel 1986, p. 18), ele procura descrever um modo de negação que não se resuma à noção kantiana de "oposição real”, já que o conceito kantiano não pode reconhecer objetos cuja essência não seja substancial, mas que seja baseada em uma experiência eminentemente negativa. Experiência claramente descrita, por exemplo, em afirmações como: "A essência, enquanto se determina como fundamento, determina-se como o não determinado (Nichtbestimmte) e é apenas a superação (Aufheben) de seu ser determinado (Bestimmtseins) que é seu determinar" (Id., Ibid. 1986, p. 81). Ver isto como a expressão do aprendizado de um exercício de auto-restrição no qual descubro algo não muito diferente da platitude de minha liberdade terminar lá onde começa a liberdade do outro não me parece uma leitura muito condizente com o que Hegel procura. Tomemos, por exemplo, a famosa afirmação de Hegel, que leva a dialética do senhor e do escravo a um certo nível de resolução:

O trabalho é desejo refreado (gehemmte Begierde), um desvanecer contido, ou seja, o trabalho forma. A relação negativa para com o objeto toma a forma do objeto e permanece, porque justamente o objeto tem independência para o trabalhador. Esse meio-termo negativo ou agir formativo é, ao mesmo tempo, a singularidade, ou o puro-ser-para-si da consciência que agora no trabalho se transfere para fora de si no elemento do permanecer; a consciência trabalhadora chega assim à intuição do ser independente como intuição de si mesma (...) no formar da coisa, torna-se objeto para o escravo sua própria negatividade (Id., 1992, p.132).

Por refrear o impulso destrutivo do desejo em seu consumo do objeto, o trabalho forma, isto no sentido de permitir a auto-objetivação da estrutura da consciência-de-si em um objeto que é sua duplicação. Mas notemos a natureza do giro dialético: o fato do objeto ter independência em relação ao trabalhador não é apenas índice de alienação no trabalho. A confrontação tanto 
com o meu agir enquanto uma essência estranha, enquanto agir para-um-Outro absoluto, quanto com o objeto enquanto aquilo que resiste ao meu projeto, tem caráter formador por abrir a consciência à experiência de uma alteridade interna como momento fundamental para a posição da identidade. Ao dizer que, no formar, torna-se objeto para a consciência sua própria negatividade, Hegel lembra como a indeterminação do desejo da consciência, ou seja, esta tentativa de ser puro-ser-para-si, "toma a forma do objeto", "agora no trabalho se transfere para fora de si". Assim, a consciência encontra no outro a mesma negatividade, a mesma indeterminação que constitui sua essência. Longe de ser uma afirmação de indivíduos que aprendem a se auto-restringir, aprendendo com isto a negociar seus sistemas particulares de interesses, temos algo totalmente diferente aqui. Na verdade, através do trabalho, o sujeito não expressa suas qualidades e interesses, o conceito hegeliano de trabalho não é expressivista. Estaremos mais perto de Hegel se dissermos que, através do trabalho, o sujeito exterioriza sua essência negativa, descobre-se como negatividade em si, permitindo que tal negatividade tenha uma forma. Talvez isto explique por que o trabalho, na Fenomenologia do Espírito, não nos coloca no caminho da "institucionalização da identidade do Eu" (Habermas 2007, p. 196), mas no recobrimento da minha negatividade e da negatividade que vem do outro (fórmula kojèveana que, ao menos neste ponto, é muito mais próxima do texto hegeliano do que a saída proposta por Honneth).

Por projetar o conflito de interesses individuais como base da luta hegeliana de reconhecimento ${ }^{18}$, Honneth poderá compreender até mesmo a luta marxista de classes dentro de um quadro de exigências morais de auto-realização individual e de estima simétrica entre sujeitos. Ele se apoia em certas tendência detecta-

18 Como fizeram também PINKARD Terry, Hegel's Phenomenology: The Sociality of Reason, Cambridge, Cambridge University Press, 1994 e HABERMAS, Jürgen : Verdade e justificação : ensaios filosóficos, Belo Horizonte : Loyola, 2004. 
das nos escritos político-históricos e nos escritos de juventude de Marx para afirmar:

a luta de classes não significa para ele, primeiramente, um afrontamento estratégico visando a aquisição de bens ou de instrumentos de poder. Ela constitui um conflito moral cuja questão é a 'emancipação' do trabalho, condição essencial de que depende, ao mesmo tempo, a estima simétrica entre sujeitos e a consciência individual de si (Honneth 1992, p. 233).

No entanto, há uma dificuldade importante a ser salientada nesta estratégia. Vimos até agora como Honneth funda o sofrimento de injustiça e desprezo, que nos levam à ação política, em um terreno pré-político, marcado por questões constitucionais normalmente ligadas à discussão sobre a gênese da individualidade moderna, da "consciência individual de si". Ou seja, a própria gênese da individualidade moderna aparece como um problema pré-político. Algo que deve ser politicamente confirmado, e não politicamente desconstruído. Desta forma, os sentimentos de injustiça e desprezo são normalmente compreendidos como resultantes do bloqueio da possibilidade de afirmação social e de reconhecimento jurídico de traços da identidade individual. Ou seja, ao menos neste caso, reconhecimento e identidade caminham necessariamente juntos.

Isto talvez explique por que os exemplos privilegiados de lutas de reconhecimento para Honneth sejam as lutas pela afirmação das "diferenças antropológicas"19 próprias às lutas feministas, assim como aquelas pelos direitos dos negros e homossexuais. Elas seriam exemplos deste: "processo prático no interior do qual experiências individuais de desprezo são interpretadas como vivências típicas de todo um grupo, de forma a motivar a reivindicação coletiva de ampliação de relações de reconhecimento"(Honnet

19 Sobre o conceito de "diferença antropológica" ver, sobretudo, Balibar 2011. 
1992, p. 260). Ou seja, experiências de desprezo ligadas a atributos de indivíduos em afirmação de suas diferenças culturais são interpretadas como violência que não afetam apenas o Eu individual. No entanto, ainda não saímos da esfera da afirmação de atributos individuais da pessoa e da construção social de identidades.

Isto explica, por exemplo, por que sua recuperação do conceito de "patologias sociais" será, em larga medida, ligada às discussões sobre o bloqueio nas "condições sociais de auto-realização individual” (Id., 2006, p. 35). Como se a realização de si devesse, naturalmente, ser pensada respeitando as estruturas do indivíduo ou, segundo Honneth leitor de Freud, as estruturas do "ego racional". Por outro lado, isto nos explica por que os modelos privilegiados por Honneth de sofrimento sejam a anomia social e o sofrimento de indeterminação identitária (Id., 2005).

\section{Modelos de patologias sociais}

Aqui, devemos fazer uma precisão. Normalmente, as discussões sobre anomia insistem no enfraquecimento da normatividade social devido ao desenvolvimento exponencial das demandas individuais. Como se as demandas de liberdade individual explodissem o quadro de regulação das normatividades sociais. Daí por que Durkheim teria de constantemente insistir que: "o indivíduo, por si mesmo, não é um fim suficiente à sua atividade. Ele é muito pouco. Não apenas limitado no espaço, ele é estreitamente limitado no tempo" (Durkheim 2005, p. 224).

Mas, na verdade, temos anomia não porque a individualidade levanta demandas particulares e identitárias específicas que não poderiam ser realizadas pela ordem social. Uma situação como esta não gera anomia, mas, se quisermos utilizar um termo proposto por Durkheim, "egoísmo" ou, ainda, revoltas políticas direcionadas ao reconhecimento de particularidades ou à ampliação do direito de escolha e decisão. Temos anomia quando as demandas deixam de ser determináveis, deixam de ter forma específica 
devido a um enfraquecimento das normas com sua capacidade de individualização e de limitação das paixões. Por isto, ao falar das causas sociais do suicídio, Durkheim deve lembrar que os suicídios motivados pela anomia se distinguem tanto daqueles motivados por uma individualização excessiva (os suicídios egoístas) quanto dos motivados por uma individualização insuficiente (suicídios altruístas). Neste contexto de anomia, ao contrário, entra-se em um "estado de indeterminação" (Durkheim 2005, p. 275 (ou, se quisermos utilizar um vocabulário de Honneth, em um "sofrimento de indeterminação") no qual nenhuma individualização é possível devido ao fato de a sociedade estar, entre outras coisas, submetida à: "inorganização característica de nosso estado econômico" (Id., Ibid. 2005, p. 286) com sua "sede de coisas novas, de gozos ignorados, de sensações inominadas, mas que perdem todo seu sabor desde que são conhecidos" (Id., Ibid. 2005, p. 285). Diante de promessas constante de gozo produzidas pela sociedade capitalista em ascensão, toda satisfação limitada é insuportável exatamente por ser uma limitação, toda escolha identitária é sem sentido exatamente por ser uma multidão de recusas. Daí as reprimendas de Durkheim contra "este mal do infinito, que a anomia aporta sempre consigo” (Id., Ibid. 2005, p. 304) e que só pode produzir cólera, decepção e lassidão exasperada por uma sensibilidade superexcitada.

Como Durkheim opera com um conceito quantitativo de diferença entre normal e patológico (Id., 2004), ele reconhecerá que um certo grau de anomia é necessário: "toda moral do progresso e do aperfeiçoamento é inseparável de um certo grau de anomia”(Id., 2005). No entanto, algo nas condições particulares do progresso em nossa sociedade produz uma situação anormal e patológica de anomia. Contra isto, Durkheim sugere um reforço das estruturas institucionais que passe, sobretudo, pela consolidação de vínculos comunitários ligados aos agrupamentos profissionais.

Quando recuperar o conceito de patologia social, Honneth irá à sua maneira partir deste diagnóstico de Durkheim, mas agora 
acrescentando um elemento a mais. Trata-se da compreensão de como, nos últimos trinta ou quarenta anos, esta situação de anomia social foi institucionalizada, transformando-se em um modo de gestão do sofrimento social e uma mola propulsora da ideologia do capitalismo. Lembremos aqui de afirmações como

"expectativas de auto-realização individual, que cresceram rapidamente devido a uma combinação historicamente única de vários processos distintos de individualização nas sociedades ocidentais dos últimos trinta, quarenta anos e que, neste tempo, tornaram-se tão claramente um padrão institucionalizado de expectativas da reprodução social, perderam seu propósito (Zweckbestimmung) interno e, mesmo assim, tornaram-se a base de fundamentação do sistema. O resultado desta inversão paradoxal, na qual processos que outrora prometeram um crescimento qualitativo da liberdade tornam-se agora ideologias da desinstitucionalização, é a emergência de vários sintomas individuais de vazio interior, de sentimento de ser supérfluo e desprovido de determinação" (Honneth 2010, p. 207-208).

Como podemos perceber, o diagnóstico não poderia ser mais próximo do quadro fornecido por Durkheim. Exigências de auto-realização individual se transformaram em "ideologias da desinstitucionalização", ou seja, em processo de enfraquecimento da capacidade de coesão e organização das normas sociais. Com isto, produz-se uma desregulação das normas sociais paga com patologias ligadas ao sentimento de esvaziamento e à incapacidade de ação.

Assim como teóricos sociais como Luc Boltanski e Eve Chiapello (1999), Honneth compreende claramente como tal anomia virou uma "força produtiva" da economia capitalista em era de flexibilização e desregulação contínua. Ele compreende também como tal gestão social da anomia é paga com o desenvolvimento exponencial de patologias ligadas à desregulação da capacidade de constituir identidades, como a depressão e seu "cansaço de ser 
si mesmo" (Ehenberg 2000), a insegurança narcísica e os transtornos de personalidade borderline. Mas, como gostaria de insistir, sua resposta não parece escapar da procura em reconstruir as bases normativas para institucionalidades capazes de garantir o desenvolvimento bem sucedido de indivíduos.

\section{Flexibilidade e fusão em uma partida de futebol}

Analisemos melhor este ponto. De fato, Honneth tende a pensar as formas de patologia social a partir da generalização do quadro da anomia. Mesmo suas discussões sobre reificação enquanto modelo de comportamento objetivante fundado sobre um pretenso "esquecimento do reconhecimento" não insistirão na crítica estrutural do caráter restritivo da identidade e da individualidade presente nas reflexões marxistas sobre a alienação social ${ }^{20}$. Ou seja, elas não exploram certas possibilidades importantes na articulação entre a problemática luckasiana da reificação e o problema marxista da alienação. No entanto, Honneth sabe que a teoria crítica pressupõe um ideal normativo de sociedade incompatível com as premissas individualistas da tradição liberal. O que não implica, em seu caso, compreender a força de descentramento que o conceito de reconhecimento pode ter em relação a um modelo que poderíamos chamar de "egológico" de organização da experiência subjetiva ${ }^{21}$. Pois não basta afirmar, por exemplo,

20 Lembremos como, em Marx, a alienação não está ligada apenas à espoliação econômica na esfera do trabalho (neste ponto, Honneth tem razão). Devido à divisão do trabalho, ela está ligada ao caráter restritivo das identidades sociais, com a assunção de si enquanto pessoa funcionalizada. A alienação em Marx é resultado do caráter restritivo da identidade social. O que explica por que a revolução só pode ser feita pela classe dos despossuídos de predicado e profundamente despossuídos de identidade. Classe formada por: "indivíduos histórico-universais, empiricamente universais, em vez de indivíduos locais” (Marx 1971, p. 58). Classe destes sujeitos sem predicados que, como diz a Ideologia alemã, poderão se satisfazer ao pescar de dia, pastorear à tarde e fazer crítica à noite, sem ser pescador, pastor ou crítico, ou seja, sem permitir que o sujeito se determine inteiramente em seus predicados.

21 O que é o caso de outros frankfurtianos como, por exemplo, Theodor Adorno. Basta levarmos em conta a diferença entre seu conceito de mimesis e as compreensões 
que "reconhecer alguém significa perceber nele qualidades que nos incitam a comportarmo-nos não mais de maneira egocêntrica, mas conforme as intenções, necessidades ou desejos desta outra pessoa" (Honneth 2006, p. 261). Insistir na força de descentramento do conceito de reconhecimento passa por reconhecer, no outro, algo que não pode ser pensado sob a forma de intenções, necessidades ou desejos de uma pessoa jurídica dotada de direitos positivos. Não se trata de novos desejos, necessidades e intenções que se desenvolvem sob a pressão de transformações históricas gerais. Trata-se de saber reconhecer o mal-estar relacionado à pessoa como modo de organização da subjetividade.

Honneth não é completamente indiferente a tais questões. Tanto que ele se vê obrigado a pensar como seu conceito de indivíduo pode dar conta do processo contemporâneo de flexibilização de identidades fixas e rígidas. Processo chamado por ele de "pluralização intrapsíquica dos sujeitos" (Id., Ibid. 2006, p. 328). Pois ele sabe que

conceitos como "identidade" e "si" designam, nas correntes mais avançadas da tradição sociológica, apenas operações de síntese que o sujeito deve efetuar para poder perceber uma multitude de experiências, de convicções e de ações pertencentes a planos temporais e sociais díspares como manifestações coerentes de um mesmo eu (Id., Ibid. 2006, p. 328).

Levando isto em conta e baseando-se em trabalhos do psicanalista Hans Loewald, Honneth chega mesmo a falar da necessidade de se abandonar temporariamente as experiências que dissolvem os limites do Eu permitindo o retorno para aquém das diferenciações intrapsíquicas que se consolidaram através de pro-

recentes das teorias cognitivas que trabalham a importância da imitação e da empatia no desenvolvimento psicológico, teorias nas quais Honneth se apoia. A respeito da força de descentramento do conceito adorniano de mimesis, ver Früchtl 1986 e Safatle 2005 . 
cessos de maturação ${ }^{22}$. Esta seria uma maneira de sua teoria dar conta da necessidade de crítica ao caráter restritivo de identidades pessoais, sem com isto flertar com a temática da negatividade e apelar a conceitos psicanalíticos como a pulsão de morte.

Exemplos dessas experiências de abandonos temporários a estados de indiferenciação pré-egóica e de fusão seriam: "o sentimento de ser parte de uma massa em celebração, em estádios de futebol, em concertos de rock ou no isolamento de um grupo de trabalho que perdeu o sentimento do tempo e se vê como se estivesse a brincar" (Honneth 2010, p. 205). Mas há algo de relativamente pobre em acreditar, por exemplo, que concertos de rock e jogos de futebol possam aparecer como bons exemplos de manifestações de uma fusão pré-egóica capaz de dar conta de nosso mal-estar diante de identidades fortemente consolidadas. Pois estamos aqui diante de fenômenos profundamente assimilados pelo funcionamento normal de nossas sociedades capitalistas do espetáculo. Estranho não se perguntar se tais fenômenos não seriam, ao contrário, exemplos bastante ilustrativos da reificação identitária produzida pelas dinâmicas atuais do universo do consumo. Não há identidade mais defensiva, exclusivista e estereotipada do que aquela que fornece o vínculo entre torcedores de futebol ou fãs de um grupo de rock. Mas quem começou achando que tudo começou bem no colo da mãe não terá dificuldade em acreditar que tudo terminará ainda melhor em um bom jogo de futebol ${ }^{23}$.

22 Ver afirmações de Hans Loewald como: "O ego media, unifica, integra porque é de sua essência manter a unidade original em níveis cada vez mais complexos de diferenciação e objetivação da realidade"(Loewald 2000, p. 11).

23 Notemos como, neste ponto, Winnicott é muito menos relacionista do que Honneth. Basta tirar as consequencias de passagens como: "Na vida da criança normal, o descanso deve incluir o relaxamento e a regressão para a não integração. Gradualmente, à medida que o self se desenvolve em força e complexidade, essa regressão à não integração aproxima-se mais e mais do doloroso estado de desintegração 'enlouquecedora'. Existe portanto um estado intermediário, no qual um bebê cuidado e em pleno desenvolvimento pode relaxar e não integrar-se, e tolerar (mas apenas tolerar) sentir-se 'louco' no estado não integrado. Em seguida é dado um passo adiante, um passo em direção à independência, e à perda para sempre da capacidade de não integração, exceto na loucura ou nas condições especializadas fornecidas pela 


\section{O deficit de negatividade e seus descontentes}

A limitação especulativa de Honneth neste ponto, com suas consequências políticas evidentes, talvez seja, no entanto, apenas o resultado de sua impossibilidade em pensar de maneira adequada a teoria freudiana das pulsões, em especial a pulsão de morte. Honneth acredita que a teoria crítica deveria se abster de uma teoria das pulsões, reduzindo a experiência subjetiva da negatividade a um "resultado inevitável de nossa socialização". Por ver a negatividade subjetiva apenas como resultado de processos de socialização, e não como determinação essencial da condição humana, ele deve reduzi-la à manifestação de tendências agressivas, antissociais ou autodestrutivas a serem superadas. Daí se segue uma pergunta como:

Por que uma teoria crítica da sociedade apenas poderia ser considerada 'crítica' se suas premissas teóricas sobre a socialização aceitassem a existência de um conflito estrutural, expresso por meio da 'negatividade' do sujeito, entre o indivíduo e a ordem social? (Winnicott 2000, p. 210).

Inicialmente, notemos que essa maneira de colocar o problema já é prenhe de pressuposições. O conflito estrutural freudiano não é exatamente entre indivíduo e ordem social. Na verdade, ele é interno ao individuo, é entre o indivíduo e ele mesmo. Por não poder se constituir como instância unitária, o indivíduo acabará por projetar seu conflito interno, transformando-o em diferença externa entre si mesmo e a ordem social.

Por outro lado, se o sujeito recorre à negatividade como modo fundamental de expressão subjetiva é por haver algo de profundamente alienante nos modelos de determinação identitária for-

psicoterapia" (Winnicott 2000, p. 139). Ou seja, para Winnicott, descrente da força terapêutica do rock, assim que o Eu se forma, não há como integrar periodicamente estados de indiferenciação intrapsíquica, a não ser sua sombra empalidecida. 
necidos pela ordem social atual, o que leva sujeitos a procurar a experiência da negatividade como modo de manifestação daquilo que ainda não tem imagem no interior de nossas formas de vida e no interior das diferenças antropológicas disponíveis.

Mas é verdade que o apelo freudiano a uma pulsão de morte parece transformar a negatividade em uma "força quase natural" que nos levaria a uma "constituição pré-social do sujeito". De fato, sabemos como, ao menos segundo Freud, a ideia de uma tendência pulsional à morte não era apenas uma hipótese referente ao comportamento humano, mas uma hipótese biológica fundamental para todo e qualquer organismo (como podemos ver em Para além do princípio do prazer). No entanto, as discussões a respeito do conceito freudiano deveriam começar por se perguntar sobre a pertinência desta hipótese biológica. Neste sentido, é interessante lembrar como filósofos ligados à reflexão sobre a biologia, como Georges Canguilhem, declaravam não ver em que a teoria freudiana deveria ser refutada (Canguilhem 1990). Trabalhos recentes em biologia, como os que podemos encontrar em Henri Atlan (1979 e 2006) e Jean Claude Ameisen(2003) poderiam corroborar a hipótese. Isto implica que uma parte significativa da discussão deve passar pela avaliação da plausibilidade da defesa da pulsão de morte como hipótese biológica, o que não ocorre em Honneth.

$\mathrm{Na}$ verdade, ele se contenta em afirmar que a agressividade não é a expressão de uma pulsão endógena. Seguindo Winnicott, ele prefere afirmar que ela seria "expressão de uma espécie de experimento ontológico visando testar a independência do mundo" (Winnicott 2000, p. 220)24 e sua resistência à minha capacidade de agressão. Da mesma forma, as tendências antissociais não precisariam ser explicadas a partir de uma pulsão, mas entrariam na conta de um impulso constante em negar a intersubjetividade,

24 Para o problema da tendência antissocial em Winnicott, ver Winnicott 2000, p. 406417. 
regredindo a um estado de fusão com objetos primários. Lendo assim, ele pode afirmar se tratar de episódios de fusão, e não de fases, administrados por um Eu maduro. Por isto, Honneth pode se perguntar: "Por que a ideia de uma disposição constante à fusão contradiria o conceito de reconhecimento?" (Winnicott 2000, p. 223); mesmo que, para isto, ele deva esquecer que, na perspectiva freudiana, a pulsão responsável pela constituição de fusões e unidades é a pulsão de vida, e não a pulsão de morte.

De toda forma, não é totalmente correto ver na pulsão de morte apenas figuras da agressividade e de tendências antissociais. Esta é uma de suas figuras sociais possíveis, mas está longe de ser a única ${ }^{25}$. Ela também pode aparecer, por exemplo, como sexualidade polimórfica e fragmentária (Laplanche 1997)². Mas principalmente, ao compreender imediatamente a pulsão de morte como puro instinto de destruição, acabamos por não tematizar, de maneira adequada, as discussões psicanalíticas sobre experiências produtivas de indeterminação, negatividade e de despersonalização (ou, ainda, de destituição subjetiva). Se seguirmos a via de Honneth, tais experiências acabarão por se transformar em experiências compensatórias postas para flexibilizar um conceito de individualidade ainda fortemente caracterizado por sua necessidade em preservar estruturas identitárias fundamentais do indivíduo moderno.

Tal perspectiva baseada na recusa ao conceito de pulsão de morte tem ainda um impacto importante nas discussões sobre patologias sociais. Pois ela nos impede de perceber a especificidade da categoria de mal-estar (Unbehagen) em Freud. Conceito central por descrever a existência de um sofrimento social maior relativo não à desregulação das normas sociais, mas à própria norma-

25 Embora esta seja, de fato, a leitura mais corrente, como podemos ver, por exemplo, em Kernberg 2009).

26 Laplanche demonstrou como a natureza disruptiva da pulsão sexual na primeira tópica freudiana acabou por alojar-se nas discussões sobre a pulsão de morte na segunda tópica. 
tividade dos processos de individuação e de personalização, tais como desenvolvidos no processo civilizatório ocidental e moderno, a noção freudiana de mal-estar pode fornecer uma perspectiva de avaliação de patologias sociais distinta daquela baseada na hegemonia do diagnóstico de anomia. Pois o conceito freudiano nos lembra como "o homem se torna neurótico porque não pode suportar a medida de privação que a sociedade lhe impõe, em prol de seus ideais culturais" (Freud 2010, p. 45). Assim: "não apenas a civilização está fundada sobre um desvio da libido a seu favor, mas ela deve igualmente procurar controlar as formas diferentes de revolta da libido contra sua dominação" (Renault 2008, p. 276). Notemos, no entanto, que tal privação de satisfação libidinal não está simplesmente vinculada à recusa da fantasia da onipotência do desejo. A renúncia pulsional é também recusa à polimorfia e à fragmentação de uma sexualidade estruturalmente dispersiva e de uma estrutura pulsional sem telos definido, pois sem objeto natural. Recusa que visa assegurar o ordenamento e a hierarquia dos prazeres ligados à reiteração dos limites identitários do Eu.

Por outro lado, poderíamos dizer ser bem provável que tal mal-estar freudiano ligado à individualidade moderna não se resolva através de experiências controladas de fusão em figuras disciplinares próprias a nossas sociedades do espetáculo. Na verdade, como gostaria de mostrar em outro artigo, ele pediria a invenção de um espaço propriamente político, no qual seriam possíveis processos de referência a si radicalmente antipredicativos ${ }^{27}$. Ou seja, um espaço no qual as demandas de reconhecimento não poderiam ser enunciadas na forma de predicados da pessoa individualizada.

É possível encontrar fundamentos importantes para aquilo que poderíamos chamar de "reconhecimento antipredicativo" se nos atentarmos às experiências produtivas de indeterminação que permitiram Lacan afirmar que a subjetivação da pulsão de morte é 
processo fundamental no tratamento analítico por poder nos levar a uma "sublimação criacionista" (Lacan 1986, p. 251). Por compreender o Eu como uma unidade narcísica que desenvolve relações intersubjetivas, em larga medida, projetivas e marcadas pela agressividade, assim como por compreender a personalidade psicológica como uma construção de sintomas defensivos, Lacan precisa insistir na necessidade do tratamento analítico apelar a uma dimensão não egológica da subjetividade. Sua maneira de pensar as distinções entre sujeito e Eu funda-se na defesa de modos de síntese que não se decalcam do modelo de unidade próprio a um Eu.

No caso de Lacan, tal estratégia passa, em larga medida, pela reconstrução do conceito de pulsão de morte a partir de uma impulsão fornecida por suas leituras da Begierde hegeliana. Inspirado em Hegel lido por Kojève, Lacan dirá que a característica fundamental do desejo é ser desprovido de procedimento de objetificação. Neste sentido, o desejo que procura reconhecimento só poderia ser compreendido de maneira antipredicativa, por ser desejo de "nada de nomeável" (Id., 1978, p. 261). Tal desejo se vincula a um profundo sentimento de indeterminação que não pode ser compreendido apenas como fonte de sofrimento, mas também como estágio fundamental de autoafirmação. Por sua vez, tal indeterminação é um espaço nunca completamente estruturado que, como gostaria de defender, aparece como dimensão fundamental da experiência negativa da liberdade. Uma negatividade que nos lembra que sujeitos podem sofrer por não alcançarem uma individualidade desejada, mas eles também sofrem por serem apenas um indivíduo e por não saberem o que fazer com experiências que aparecem, para o Eu, como profundamente indeterminadas ${ }^{28}$. Em outro texto, gostaria de expor como tal experiência de indeterminação pode ter uma força política importante. Pois ela libera os conflitos de reconhecimento do terreno das diferenças culturais, com seus processos de constru- 
ção e afirmação de identidades enquanto atributos da pessoa, nos abrindo a possibilidade de fundar ontologicamente uma zona de reconhecimento propriamente político. Um reconhecimento político para além dos embates culturais sobre identidades.

\section{Bibliografia}

ADORNO, Theodor. "Sobre a relação entre psicologia e sociologia” In: Escritos de psicologia e psicanálise. São Paulo: Unesp (no prelo).

AMEISEN, Jean Claude. La sculpture du vivant: le suicide cellulaire et la mort créatrice. Paris: Seuil, 2003.

ARANTES, Paulo Eduardo. "Um Hegel errado, mas vivo", Revista Ide, n. 21, 1991.

ATLAN, Henri. Entre le cristal et la fumée: essai sur l'organisation du vivant. Paris: Seuil, 1979.

L'organisation biologique et la theorie de l'information. Paris: Seuil, 2006.

BADIOU, Alain. São Paulo: a fundação do universalismo. São Paulo: Boitempo, 2009.

BEBEE, Beatrice e LACHMANN, Frank. Infant research and adult treatment: co-constructing interactions. Hillsdale: Analytic Press, 2002.

BOLTANSKI, Luc e CHIAPELLO, Eve. Le nouveau esprit du capitalism. Paris: Gallimard, 1999.

BRATEN, Stein (org.). On being moved: from the mirrors neurons to empathy. Philadelphia: John Benjamin Publisher House, 2007.

BUTLER, Judith. Subjects of desire:hegelians reflections in twenty century France. Nova York: Routledge, 2 ed., 2012.

CANGUILHEM, Georges. "Vie", In: Enciclopaedia universalis, Paris: Enciclopaedia Universalis France, 1990. 
DAVIDSON, Arnold. The emergence of sexuality: historical epistemology and the formation of concepts. Harvard: Harvard University Press, 2004.

DELEUZE, Gilles e GUATTARI, Félix. O anti-Édipo: capitalismo e esquizofrenia. São Paulo: Editora 34, 2014.

DESCOMBES, Vincent. Le même et l'autre: quarrante e cinq ans de philosophie française. Paris: Minuit, 1979.

DURKHEIM, Emile. Les règles de la pensée sociologique. Paris: Flammarion, 2004. Le suicide. Paris: PUF, 2005.

EHRENBERG, Alain. La fatigue d'être soi. Paris: Odile Jacob, 2000.

FONAGY, Peter e TARGET, Mary. "Playing with reality: a theory of external reality rooted in intersubjectivity”, International Journal of Psychoanalysis. 2007, n. 88, p. 917-937.

FOUCAULT, Michel. Os anormais. São Paulo: Martins Fontes, 2010.

FREUD, Sigmund. Gesammelte Werke (GW) vol. XV, Frankfurt: Fischer, 1999.

O mal-estar na civilização. In: Obras completas vol. XVIII. São Paulo: Companhia das Letras, 2010.

FRÜCHTL, Josef. Mimesis : Konstellation eines Zentralbegriffs bei Adorno. Würzburg: Königshausen \& Neumann 1986.

GALLAGHER, Shaun e VARGA, Somogy. "Critical social philosophy, Honneth and the role of primary intersubjectivity", European Journal of Social Theory. 2012 15: 243, p. 255).

HABERMAS, Jürgen. Técnica e ciência como ideologia. Lisboa: Edições 70, 2007.

Verdade e justificação: ensaios filosóficos. Belo Horizonte: Loyola, 2004.

HACKING, Ian. Historical ontology. Harvard: Harvard University Press, 2004 .

HEGEL, G.W.F. Fenomenologia do Espírito. Petrópolis: Vozes, 1992. 
HEGEL, G.W.F. Wissenschafr der Logik I und II. Frankfurt: Suhrkamp, 1986.

HONNETH, Axel. Das Ich im Wir. Frankfurt: Suhrkamp, 2010. Kamp um Anerkennung: Zu moralischen Grammatik sozialer Konflikte. Frankfurt: Suhrkamp, 1992.

Pathologien der Vernunft: Geschichte und Gegenwart der Kritischen Theorie. Frankfurt: Suhrkamp, 2008. La société du mépris. Paris: La Découverte, 2006. Sofrimento de indeterminação. São Paulo: Esfera Pública, 2005.

Verdinglichung: eine annerkenungstheoritische Studie. Frankfurt: Suhrkamp, 2005.

KERNBERG, Otto. "The concept of death drive: a clinical perspective", International Journal of Psychoanalysis, vol. 90, n. 5, 2009 .

LACAN, Jacques. Seminário I. Rio de Janeiro: Jorge Zahar, 1986. Séminaire II. Paris: Seuil, 1978. Séminaire V. Paris: Seuil, 1998. Séminaire VII. Paris: Seuil, 1986. Séminaire XI. Paris: Seuil, 1973. Seminário XXIII: O Sinthoma. Rio de Janeiro: Jorge Zahar, 2010.

LOEWALD, Hans; Collected Papers and monographs, Hagerstown, MD: University Publishing group, 2000.

MARCUSE, Herbert. Eros e civilização. Rio de Janeiro: LTC, 1999.

MARX, Karl. A ideologia alemã. Rio de Janeiro: Civilização Brasileira, 1971.

O'HARA, M. "Postpartum depression: what we know", Journal of Clinical Psychology, V. 65, Issue 12, 2009.

PINKARD Terry. Hegel's Phenomenology: The Sociality of Reason. Cambridge: Cambridge University Press, 1994.

REICH; Wilhelm. Análise do caráter. São Paulo: Martins Fontes, 2001. 
RENAULT, Emmanuel. Souffrances sociales: philosophie, psychologie et politique. Paris: La découverte, 2008.

ROTH, Michael. Knowing and history: appropriations of Hegel in twentieth century France. Ithaca, N. Y.: Cornell University Press, 1988.

SAFATLE, Vladimir. Grande Hotel Abismo: por uma reconstrução da teoria do reconhecimento. São Paulo: Martins Fontes, 2012. A paixão do negativo: Lacan e a dialética. São Paulo: Unesp, 2006.

"Espelhos sem imagens: mimesis e reconhecimento em Adorno e Lacan”. Revista Trans/form/ação, vol. 28, n. 2, 2005. TAYLOR, Charles. Multiculturalism and the "politics of recognition", Princeton: Princeton University Press, 1992.

TOMASELLO. Michael. The cultural origin of human cognition. Harvard: Harvard University Press, 2003.

VAN HAUTE, Philippe e DE VLEMINCK, Jens. "Aan gene zijde van Freud: De grenzen en de mogelijkheden van een psychoanalytische pathoanalyse" In: Idem; Freud als filosoof, Kalmthout: University of Leuven Press, 2013.

WHITEBOOK, Joel. "First nature and second nature in Hegel and psychoanalysis", Constellations, vol. 15, n. 3, 2008.

WINNICOTT, Donald. Da pediatria à psicanálise. Rio de Janeiro: Imago, 2000.

Natureza humana. São Paulo: Imago, 1990. 